\title{
REPLACEMENT VERSUS NON-REPLACEMENT OF THE PATELLAR JOINT SURFACE IN TOTAL KNEE ARTHROPLASTY
}

\author{
SUBSTITUICCÃO VERSUS NÃO SUBSTITUICCÃO DA SUPERFÍCIE \\ ARTICULAR DA PATELA NA ARTROPLASTIA TOTAL DE JOELHO
}

\author{
Rafael Aluisio Fenerich Honorio Ferreira ${ }^{1}$, Leonardo Barros Mascarenhas ${ }^{1}$, Rodrigo Salim ${ }^{1}$, Aline Miranda Ferreira ${ }^{1}$, \\ FABRICIO FOGAGNOLO ${ }^{1}$, MAURICIO KFURI JUNIOR ${ }^{1,2}$
}

1. Faculdade de Medicina de Ribeirão Preto da Universidade de São Paulo, Department of Locomotor Biomechanics, Medicine, and Rehabilitation, SP, Brazil. 2. University of Missouri, Department of Orthopedics, Columbia, MI.

\begin{abstract}
Objective. This study addresses functional data, pain, and the reoperation rate in patients undergoing primary total knee arthroplasty (TKA) during which the patella was or was not replaced. Methods: Fifty-three knees were included, 18 with the patella replaced and 35 with the patella not replaced. WOMAC and SF-12 scores and knee pain were analyzed preoperatively and 3,6 , and 12 months after TKA. The reoperation rate was also evaluated. Results: Both groups presented significant improvement in WOMAC score and pain at all postoperative follow-up appointments. There was no significant difference between the groups in all evaluated variables. Two subjects in the group did not undergo patellar replacement due to complaints of anterior knee pain after arthroplasty. There was no difference between the groups in relation to the reoperation rate. Conclusion: Patients receiving patellar replacement during TKA did exhibit significant differences in the rate of reoperation, function, or pain when compared to patients in which the patella was replaced. Level of Evidence III; Cohort study.
\end{abstract}

Keywords: Arthroplasty. Knee. Patella.

\section{RESUMO}

Objetivo: Este estudo confronta dados funcionais, dor e taxa de re-operação de pacientes submetidos à ATJ primária, que substituíram e que não substituíram a patela. Métodos: 53 joelhos, sendo $18 \mathrm{com}$ a patela substituída e $35 \mathrm{com}$ a patela não substituída. Womac, SF-12 e dor no joelho foram analisados no pré-operatório e após 3, 6 e 12 meses da ATJ. A taxa de re-operação também foi avaliada. Resultados: Ambos os grupos apresentam melhora significativa no questionário Womac e dor em todos os seguimentos pós-operatórios. Não houve diferença significativa entre os grupos em todas as variáveis avaliadas. Dois sujeitos no grupo NÃO foram submetidos a substituição da patela devido a queixas de dor anterior no joelho após a artroplastia. Não houve diferença entre os grupos em relação a taxa de re-operação. Conclusão: Pacientes submetidos a substituição da patela na ATJ não obtiveram diferença significativa quanto a taxa de reoperação, função e dor quando comparados aqueles que não substituíram. Nível de evidência III; Estudo Coorte.

Descritores: Artroplastia. Joelho. Patela.

Citation: Ferreira RAFH, Mascarenhas LB, Salim R, Ferreira AM, Fogagnolo F, Kfuri Junior M. Replacement versus non-replacement of the patellar joint surface in total knee arthroplasty. Acta Ortop Bras. [online]. 2018;26(3):175-8. Available from URL: http://www.scielo.br/aob.

\section{INTRODUCTION}

Disagreements on whether to replace or retain the patella during total knee arthroplasty (TKA) have been present throughout the history of knee surgery and continue, with no consensus in the current literature. Surgeons who prefer to replace the patella justify their decision by stating that this reduces the incidence of anterior knee pain, prevents future secondary revisions of the patella, provides greater patient satisfaction, improves overall function, and has a low rate of complications. Surgeons who opt not to substitute the patella indicate more physiological patellofemoral kinematics, the possibility of greater patellofemoral load support, conservation of the patellar bone, reduction of osteonecrosis of the patella, and prevention of complications associated with patellar replacement such as patella fractures, patellar ligament injury, wear or loosening of the implant, and instability. ${ }^{1,2}$ Still others maintain that replacement should be selective and based on criteria such as age, quality of the patellar cartilage, the presence of crystal deposit disease, the positioning of the patella, and femoral component type. ${ }^{3}$

Consequently, current studies comparing patients undergoing TKA with or without replacement of the patellar surface do not present a consensus regarding possible differences in the functional questionnaires, pain, or reoperation rate. 
The main objective of this study is to evaluate the functional results and reoperation rate in patients undergoing primary TKA with or without replacement of the patellar joint surface over a period of one year post-procedure.

\section{MATERIALS AND METHODS}

We retrospectively evaluated 53 subjects with osteoarthritis of the knee (OAK) who underwent TKA at our institution between January 2013 and December 2014. Inclusion criteria were subjects with primary or secondary OAK, with outpatient follow-up of at least 12 months who attended postoperative follow-up visits at three, six, and 12 months post-procedure. Exclusion criteria were previous osteoarticular infection, previous bilateral TKA, incomplete medical record data, and postoperative complications not related to the patella. The study was approved in advance by the institutional review board (CAEE 53544516.1.0000.5440).

The cases selected were subdivided into two groups: "YES" when the patella was replaced and "NO" when the surgeon did not replace it, performing patelloplasty via debridement and excision of the marginal osteophytes. The implant used for total arthroplasty was the same in all patients (PFC Sigma, Depuy-Johnson) and the surgeries were performed by senior staff in the service. The option to not replace the patella was made when the cartilage of the patellar surface did not demonstrate deep lesions, the patella was less than $20 \mathrm{~mm}$ thick, and when patellar tracking was good. The data were obtained by analyzing electronic patient records which contained the operative report, patient history and assessment of function; consequently a free and informed consent form was not required. Demographic data were collected on the subjects (age, sex, and BMI) whether the patella was replaced or not, along with the occurrence of reoperation up to the date of data collection (December, 2016). Function prior to and 3, 6, and 12 months after surgery was analyzed using the Western Ontario McMaster Universities Osteoarthritis Index (WOMAC) questionnaire, ${ }^{4}$ with 0 representing no impairment of function and 100 very compromised function, the physical and mental components of the Short Form 12 (SF12), ${ }^{5}$ and pain was measured using the visual analog scale (VAS).

\section{Statistical analysis}

The data obtained were processed using SAS Statistical Software (version 9.3; SAS Institute Inc., Cary, NC) with $5 \%$ significance ( $p$ value $\leq 0.05$ ). Mixed-effect linear regression was used to analyze the evolution of the variables WOMAC, SF12, and VAS over time in the YES and NO groups, and to establish the differences between the groups.

\section{RESULTS}

The demographic data, pre- and postoperative function, and reoperation rate for each group are presented in Table 1. No statistical difference was found in relation to BMI, age, function, or pain in the preoperative evaluation, showing homogeneity between the groups. Comparison of postoperative function between the two groups showed no significant difference in the rate of improvement in WOMAC, SF12, or VAS scores between groups at any of the postoperative follow-up visits. Two members of the group which did not receive patellar replacement were reoperated to perform patellar arthroplasty due to complaints of patellofemoral pain. One subject in the group that did receive patellar replacement and another in the group that did not receive patellar replacement underwent manipulation under anesthesia to gain flexion movement in the operated knee.

Analysis of the change in variables over time revealed that both groups had significant improvement in WOMAC scores at three, six, and 12 months postoperatively $(p<0.001)$. Pain according to the
Tabela 1. Demographic and clinical data in the pre- and post-operative periods, and reoperation rate, expressed as mean and standard deviation.

\begin{tabular}{c|c|c|c|c|c}
\hline & \multicolumn{4}{|c|}{ Patella Replacement } & \\
\hline & \multicolumn{2}{|c|}{ No (N=35) } & \multicolumn{2}{c|}{ Yes (N=18) } & P \\
\hline Age & 68.5 & -5.8 & 68.9 & 6.9 & -0.4 \\
\hline BMI & 32.2 & -4.8 & 33.5 & 4.6 & -0.34 \\
\hline
\end{tabular}

Preoperative function

\begin{tabular}{c|c|c|c|c|c}
\hline WOMAC & 60 & -16.1 & 58.7 & 13.9 & -0.78 \\
\hline Physical SF12 & 39.4 & -14.5 & 32.3 & 6.9 & -0.09 \\
\hline Mental SF12 & 39.5 & -12.5 & 49.5 & 12.7 & -0.49 \\
\hline VAS & 5.6 & -3.1 & 4.8 & 3.1 & -0.23 \\
\hline
\end{tabular}

Function 3 months post-op

\begin{tabular}{c|c|c|c|c|c}
\hline WOMAC & $19.4^{\dagger}$ & -16.5 & $21.2^{\dagger}$ & 21.1 & -0.74 \\
\hline Physical SF12 & 41.9 & -9.1 & $40.3^{\dagger}$ & 8 & -0.6 \\
\hline Mental SF12 & 44.5 & -12.4 & 51.7 & 15.1 & -0.28 \\
\hline VAS & $1.8^{\dagger}$ & -2.4 & $0.87^{\dagger}$ & 1.5 & -0.15 \\
\hline
\end{tabular}

Function 6 months post-op

\begin{tabular}{c|c|c|c|c|c}
\hline WOMAC & $16.9^{\dagger}$ & -14.3 & $18.4^{\dagger}$ & 18.9 & -0.75 \\
\hline Physical SF12 & 46.6 & -8.8 & $41.4^{\dagger}$ & 9.4 & -0.14 \\
\hline Mental SF12 & 46 & -13.7 & 51 & 9.3 & -0.38 \\
\hline VAS & $1.1^{\dagger}$ & -2 & $0.3^{\dagger}$ & 1.4 & -0.27 \\
\hline \multicolumn{6}{|c}{ Function 12 months post-op } \\
\hline WOMAC & $14.9^{\dagger}$ & 13.5 & $18.1^{\dagger}$ & 13.5 & -0.49 \\
\hline Physical SF12 & 44.8 & 9.2 & $41.8^{\dagger}$ & 10.3 & -0.33 \\
\hline Mental SF12 & 49.6 & 10.8 & 45.1 & 11.8 & -0.27 \\
\hline VAS & $1.2^{\dagger}$ & 2.1 & $0.75^{\dagger}$ & 1.4 & -0.52 \\
\hline Reoperation rate & $2(5.7 \%)$ & $1(5.6 \%)$ & \\
\hline
\end{tabular}

BMI: body mass index; VAS: visual analogue scale; post-op: post-operative. ${ }^{\dagger}$ statistical difference compared to preoperative evaluation.

VAS was significantly reduced in both groups at three, six and 12 months postoperatively $(p<0.001)$. The group which received patellar replacement showed improved scores on the physical domain of the SF12 at the follow-up assessments at three $(p=0.019)$, six $(p=0.005)$, and 12 months $(p=0.003)$ postoperatively. No significant difference was seen between pre- and postoperative assessments in the physical domain of the SF12 in the group which did not receive patellar replacement $(p>0.05)$. The mental component of the SF12 also showed no significant changes in either group ( $p>0.05)$. None of the variables showed significant differences between the assessments at three versus six months, three versus 12 months, or six versus 12 months. (Figure 1)

\section{DISCUSSION}

The patellofemoral joint and replacement of the patella are currently among the most widely discussed aspects related to TKA. Our study found no statistical difference in functional characteristics or knee pain between groups that received or did not receive patellar replacement.

The function reported by the total score of the WOMAC questionnaire was significantly better in both groups starting from three months postoperative, as was pain measured by the VAS. A meta-analysis conducted by Pilling et al. ${ }^{6}$ showed that previous pain and degree of satisfaction in patients who received patellar replacement were the same as in patients who did not receive patellar replacement. 

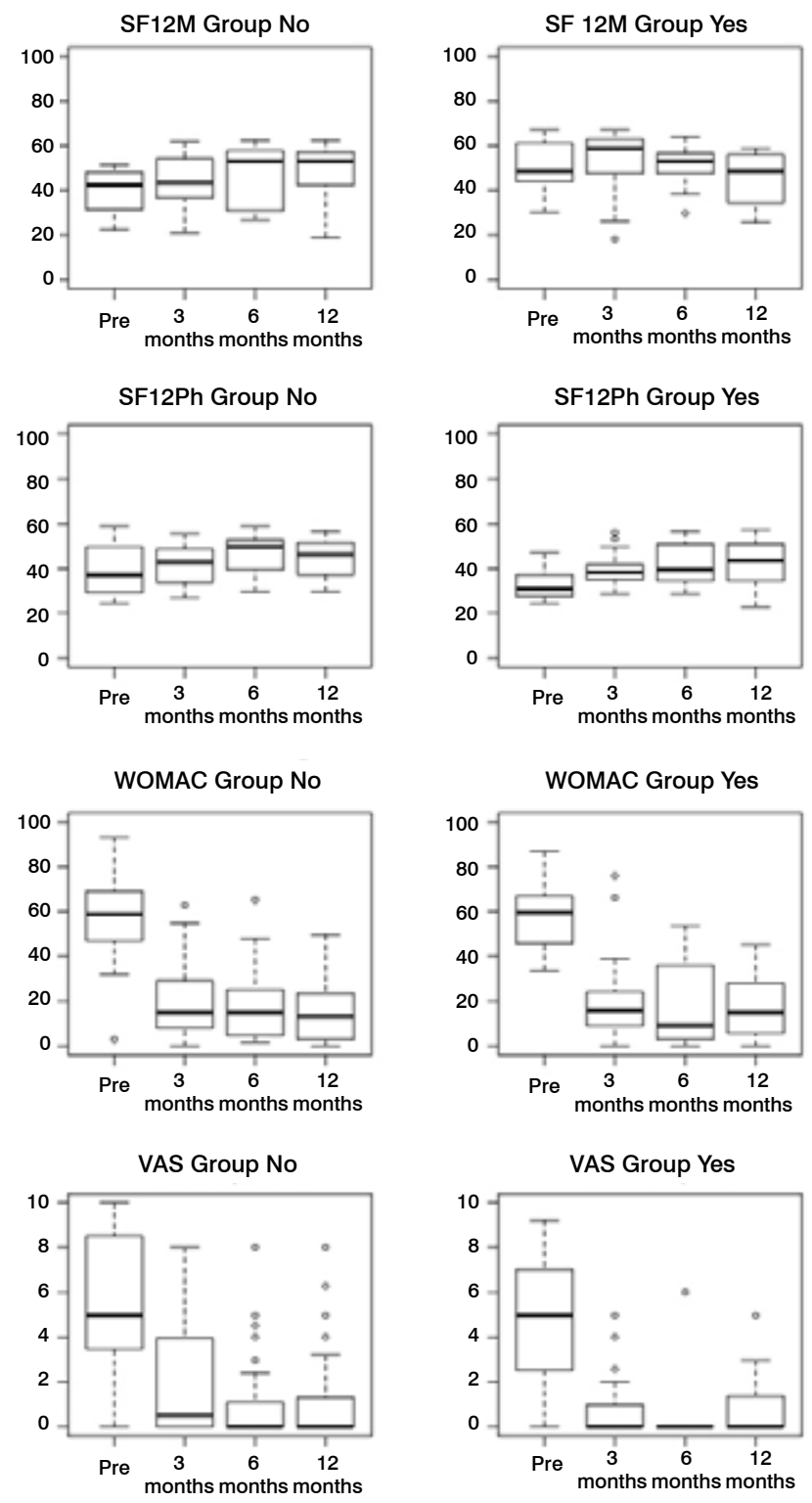

SF12M, SF12 mental component; SF12F, SF12 physical component; VAS, visual analog scale.

Figure 1. Changes in WOMAC, SF12m, and VAS score over time.

However, Chen et al. ${ }^{2}$ suggested that over the long term (five years or more), patellar replacement could yield better functional results as indicated by the Knee Society Score. A recent study by Aunan et al. ${ }^{7}$ showed that after three years, scores on the KOOS questionnaire were significantly better in patients who received patellar replacement. Beaupre et al. ${ }^{8}$ assessed the function of patients who received or did not receive patellar replacement using the WOMAC questionnaire, and found no difference between groups 1,5 , and 10 years after the procedure. The WOMAC questionnaire includes questions related to pain, stiffness, and function, and has been validated for Brazilian Portuguese; like the SF12 quality of life questionnaire, it is responsive to changes in patients with knee osteoarthritis., ${ }^{4,8-10}$ However, our study only evaluated function and pain one year post-procedure, which may not be sufficient time to analyze the benefits of replacing or not replacing the patella. Anterior knee pain is a frequent complaint in patients who undergo TKA, with an incidence exceeding 30\% according to some authors; ${ }^{11}$ the hypothesis is that replacing the patella could decrease this incidence. On the other hand, replacement of the patella can cause complications such as poor patellar alignment, sprains, avascular necrosis, failure of the extensor mechanism, fracture, etc., ${ }^{1,2}$ Studies show that the surgical reoperation rate due to patella complications is higher when the patella is not replaced. ${ }^{6,12}$ The study by Chen et al. ${ }^{2}$ showed that patella replacement can reduce the risk of reoperation by $4 \%$. Meanwhile, Breeman et $a{ }^{13}$ found that until five years after arthroplasty, the rate of reoperation, healthcare costs, and functional outcomes are similar whether the patella is replaced or not. In the present study, the time patients were followed to assess reoperation rate ranged from three to four years and no difference was found in the reoperation rate between the groups. The two patients in the group which did not receive patellar replacement who were reoperated to replace the patellar joint surface had different outcomes: one showed improvement after the surgery, while the other still had the same pain as before the revision surgery.

Rodriguez-Merchan et al. ${ }^{3}$ recommended replacing the patella when injuries classified as Outerbridge IV are present, and retaining the patella for injuries graded I, II and III. Roberts et al. ${ }^{14}$ analyzed the influence of replacing or not replacing the patella in patients who did not have exposed bone on the patellar joint surface, and the results indicated slightly greater patient satisfaction in the group where the patella was replaced, but the functional questionnaire, complication rate, and number of revisions were similar between the groups.

Patelloplasty is routinely performed in our service during TKA. Liu et al. ${ }^{15}$ studied the influence of patelloplasty and patellar replacement on the rate of reoperation, function, and pain. The results showed no difference between the groups seven years after the procedure. The authors reported a preference for patelloplasty, suggesting that this procedure preserves sufficient bone stock and can easily converted to a patellar replacement if the patient complains of anterior knee pain. Zha et al. ${ }^{16}$ found favorable results for the lateral release of the patella compared to non-release during TKA. We conduct lateral release only in cases when we observe that the tracking of the patella is not appropriate.

This study has some limiting factors. The analysis was retrospective, which did not permit standardized exploration of the degree of degeneration in the patellar articular surface. Furthermore, the sample size of this study was small, which reduces the power of the results presented. Functional assessment was only measured through self-perceived questionnaires completed by the patient about their own function. We believe that prospective randomized studies using instruments to assess physical performance may be more appropriate to determine whether replacement of the patellar surface should be routinely performed in TKA.

\section{CONCLUSION}

Total knee arthroplasty with or without patellar replacement has similar results in the first year post-procedure. Prospective studies with larger samples should be conducted.

AUTHORS' CONTRIBUTIONS: Each author made significant individual contributions to this manuscript. RS (0000-0003-3978-4888)*: conducted surgeries, drafted the text, conducted the statistical analysis, contributed to the intellectual concept and composition of the entire research project. FF $(0000-0002-6495-3383)^{*}$ and MKJ (000-0002-4111-1896)*: drafted and revised the text and contributed to the intellectual concept of the study. AMF $(0000-0002-1919-893 X)^{\star}$ : conducted the statistical analysis and drafted the text. RAFHF (0000-0002-2273-6225)* and LBM (0000-0002-2483-8356)* obtained the data and drafted the text. All authors approved the final version of the manuscript. *ORCID (Open Researcher and Contributor ID). 


\section{REFERENCES}

1. Schindler OS. The controversy of patellar resurfacing in total knee arthroplasty: Ibisne in medio tutissimus? Knee Surg Sports Traumatol Arthrosc. 2012;20(7):1227-44.

2. Chen K, Li G, Fu D, Yuan C, Zhang Q, Cai Z. Patellar resurfacing versus nonresurfacing in total knee arthroplasty: A meta-analysis of randomised controlled trials. Int Orthop. 2013;37(6):1075-83.

3. Rodríguez-Merchán EC, Gómez-Cardero P. The outerbridge classification predicts the need for patellar resurfacing in TKA. Clin Orthop Relat Res. 2010;468(5):1254-7.

4. Fernandes MI. Tradução e validação do questionário de qualidade de vida específico para a osteoartrose WOMAC (Western Ontario and McMaster Universities Osteoarthtis Index) para a língua portuguesa [dissertação]. São Paulo: Universidade Federal de São Paulo (UNIFESP); 2002.

5. Silveira MF, Almeida JC, Freire RS, Haikal DS, Martins AE. Psychometric properties of the quality of life assessment instrument: 12-item health survey (SF-12). Cien Saude Colet. 2013;18(7):1923-31.

6. Pilling RW, Moulder E, Allgar V, Messner J, Sun Z, Mohsen A. Patellar resurfacing in primary total knee replacement: a meta-analysis. J Bone Joint Surg Am. 2012;94(24):2270-8.

7. Aunan E, Næss G, Clarke-Jenssen J, Sandvik L, Kibsgård TJ. Patellar resurfacing in total knee arthroplasty: functional outcome differs with different outcome scores. Acta Orthop. 2016;87(2):158-64.

8. Beaupre L, Secretan C, Johnston DWC, Lavoie G. A randomized controlled trial comparing patellar retention versus patellar resurfacing in primary total knee arthroplasty: 5-10 year follow-up. BMC Res Notes. 2012;5(1):273.
9. Clement ND, MacDonald D, Simpson AH. The minimal clinically important difference in the Oxford knee score and Short Form 12 score after total knee arthroplasty. Knee Surg Sport Traumatol Arthrosc. 2014;22(8):1933-9.

10. Lingard EA, Katz JN, Wright RJ, Wright EA, Sledge CB, Kinemax outcomes Group. Validity and responsiveness of the Knee Society Clinical Rating System in comparison with the SF-36 and WOMAC. J Bone Joint Surg Am. 2001;83(12):1856-64.

11. Michalik R, Rath B, Springorum HR, Lüring C, Tingart M. Vorderer Knieschmerz nach Knie-TEP-Implantation: Ursachen, Diagnostik und Therapie. Orthopade. 2016;45(5):386-98.

12. Feng B, Weng XS, Lin J, Jin J, Qian WW, Wang W et al. Long term follow up of clinical outcome between patellar resurfacing and nonresurfacing in total knee arthroplasty: Chinese experience. Chin Med J (Engl). 2014;127(22):3845-51.

13. Breeman S. Patellar resurfacing in total knee replacement: five-year clinical and economic results of a large randomized controlled trial. J Bone Joint Surg Am. 2011;93(16):1473-81.

14. Roberts DW, Hayes TD, Tate CT, Lesko JP. Selective patellar resurfacing in total knee arthroplasty: A prospective, randomized, double-blind study. J Arthroplasty. 2015;30(2):216-22.

15. Liu Z tang, Fu PL, Wu HS, Zhu Y. Patellar reshaping versus resurfacing in total knee arthroplasty - Results of a randomized prospective trial at a minimum of 7years' follow-up. Knee. 2012;19(3):198-202.

16. Zha GC, Sun JY, Dong SJ. Less anterior knee pain with a routine lateral release in total knee arthroplasty without patellar resurfacing: A prospective, randomized study. Knee Surg Sports Traumatol Arthrosc. 2014;22(3):517-25. 